\title{
HUBUNGAN KESIAPAN INSTITUSI DENGAN KELULUSAN MAHASISWA D3 KEPERAWATAN DALAM MENGHADAPI EXIT EXAM
}

\author{
Rina Delfina ${ }^{1}$ Maiyulis ${ }^{2}$, Samwilson Slamet $^{3}$ \\ Universitas Bengkulu¹, Universitas Bengkulu², Universitas Bengkulu ${ }^{3}$ \\ Email : rdelfina@unib.ac.id
}

\begin{abstract}
Competency testing is carried out as a form of maintaining the quality of graduates who have competencies in accordance with nationally established standards. The exit exam can simply be interpreted as a graduation exam, meaning that if a student is unable to meet the pass mark from the exam, he or she is declared not to have passed the nursing education. The purpose of this study was to see the relationship between institutional readiness and passing the exit exam of D3 nursing students. This study uses an analytical survey with a cross sectional study approach. Collecting data using a questionnaire in the form of google form. Sampling was done by simple random sampling with a total of 110 people. The results showed that there was no relationship between institutional readiness and graduation of D3 Nursing students in facing the exit exam with a fisher ecxact value $=0.589>005$. It is hoped that there will be synergy between institutions, lecturers and students in preparation for the UKOM exit exam by discussing more standardized questions. ukom, attend tutoring and take part in internal and external try outs.
\end{abstract}

Keywords: Exit Exam, Readiness, Graduation

\begin{abstract}
Abstrak
Uji kompetensi dilakukan sebagai bentuk menjaga kualitas lulusan yang memiliki kompetensi sesuai dengan standar yang sudah ditetapkan secara nasional. Exit exam secara sederhana dapat diartikan sebagai ujian kelulusan, artinya bahwa apabila seorang mahasiswa tidak dapat memenuhi nilai batas lulus dari ujian, maka dinyatakan tidak lulus dari pendidikan keperawatan. Tujuan penelitian ini untuk melihat hubungan antara kesiapan institusi dengan kelulusan exit exam mahasiswa D3 keperawatan. Penelitian ini menggunakan survei analitik dengan pendekatan cross sectional study. Pengumpulan data menggunakan kuesioner dalam bentuk googleform. Pengambilan sampel dengan cara simple random sampling yang berjumlah 110 orang. Hasil penelitian menunjukkan tidak ada hubungan antara kesiapan institusi dengan kelulusan mahasiswa D3 Keperawatan dalam menghadapit exit exam dengan nilai fisher ecxact $=0,589>\alpha 005$. Diharapkan adanya sinergi antara institusi, dosen dan mahasiswa dalam persiapan menghadapi UKOM exit exam dengan memperbanya membahas soal-soal berstandar ukom, mengigikuti bimbingan belajar dan mengikuti try out internal maupun eksternal.
\end{abstract}

Keywords: Exit Exam; Kesiapan; Kelulusan

Jurnal Vokasi Keperawatan (JVK) Volume 4 No 2 Desember 2021 


\section{PENDAHULUAN}

Uji kompetensi keperawatan adalah proses pengukuran pengetahuan, keterampilan, dan perilaku peserta didik pada perguruan tinggi yang menyelenggarakan pendidikan tinggi bidang keperawatan. Uji kompetensi Nasional diselenggarakan oleh Perguruan Tinggi bekerja sama dengan Organisasi Profesi. Penyelenggaraan dilaksanakan oleh panitia penyelenggara yang ditetapkan melalui Keputusan Menteri Riset, Teknologi dan Pendidikan Tinggi. Ujian ini ditujukan untuk mencapai standar kompetensi lulusan yang memenuhi standar kompetensi kerja. Selain hal tersebut, Uji Kompetensi Nasional dapat dijadikan sebagai bagian dari penjaminan mutu pendidikan (Panitia Ujian Kompetensi Nasional, 2018).

Uji kompetensi dilakukan sebagai bentuk menjaga kualitas lulusan yang memiliki kompetensi sesuai dengan standar yang sudah ditetapkan secara nasional. Dengan adanya uji kompetensi ini diharapkan kualitas pelayanan yang diberikan kepada masyarakat semakin meningkat. Peningkatan kualitas pendidikan tenaga kesehatan adalah salah satu langkah strategis untuk meningkatkan ketersediaan tenaga kesehatan yang berkualitas dan memiliki kompetensi yang relevan untuk menjalankan sistem pelayanan kesehatan. Salah satu upaya yang dilakukan untuk mendorong percepatan peningkatan dan pemerataan kualitas pendidikan kesehatan adalah dengan meningkatkan kendali mutu lulusan pendidikan yang kompeten dan memperoleh sertifikat kompetensi (Notoatmojo, 2014).

Perawat sebagai bagian dari tenaga kesehatan yang terlibat langsung dalam pemberian pelayanan kepada masyarakat harus mengikuti uji kompetensi. Berbagai cara ditempuh oleh perguruan tinggi untuk meningkatkan kemampuan mahasiswanya dalam menghadapi uji kompetensi. Seluruh tenaga kesehatan termasuk didalamnya perawat harus mengikuti uji kompetensi sebagai syarat memperoleh Surat Tanda Registrasi (STR). Uji kompetensi diartikan sebagai proses pengukuran pengetahuan, keterampilan dan perilaku peserta didik pada perguruan tinggi yang menyelenggarakan program studi keperawatan dengan tujuan untuk mencapai standar kompetensi lulusan yang memenuhi standar kompetensi kerja (UU Keperawatan No. 38, 2014). Selain itu, tujuan dilakukannya uji kompetensi khususnya terhadap perawat lulusan baru adalah untuk melindungi masyarakat dengan memberikan jaminan bahwa perawat pada entry level 
registered memiliki kompetensi yang dipersyaratkan untuk dapat menjalankan praktek profesi secara aman dan efektif (Kariasa et al., 2018).

Uji kompetensi atau lisensi telah lama dilaksanakan di luar negeri. Negara pertama yang mengundang-undangkan lisensi keperawatan pada tahun 1938 yaitu New York. Kemudian tahun 1994 uji lisensi dinamakan dengan National Council Licensing Examination for Registered Nurses (NCLEXRN) yang dikenal sampai sekarang. Uji lisensi tersebut dikelola oleh National Council of State Boards of Nursing (NCSBN) (Benefiel, 2011). Di Indonesia pelaksanaan uji kompetensi mulai dilaksanakan pada 1 Agustus 2013 (RistekDikti, 2014). Dan saat ini akan diberlakukan exit exam bagi mahasiswa keperawatan. Artinya mahasiswa akan di wisuda setelah lulus dari ujian kompetensi yang dilaksanakan pada akhir semester enam. Exit exams ini mulai berlaku tahun 2021 yang ditetapkan melalui Permendikbud Nomor 2 Tahun 2020 tentang tata cara uji kompetensi mahasiswa bidang kesehatan. Pasal 3 dalam peraturan ini menegaskan dimana proporsi indeks prestasi kumulatif (IPK) dan hasil uji kompetensi diubah dengan ketentuan $60 \%$ akademik dan $40 \%$ hasil uji kompetensi untuk menentukan kelulusan tenaga kesehatan.

Uji kompetensi perawat yang menjadi ketakutan mahasiswa tahap akhir kini perlahan dibenahi dengan adanya peraturan baru yang lebih baik dan memanusiakan manusia. Banyak keuntungan yang didapatkan dari adanya peraturan tersebut salah satunya kesempatan bagi perawat yang belum lulus untuk terus berikhtiar mencintai profesinya. Harapan kedepan sekiranya uji kompetensi perawat akan mampu menghasilkan lulusan perawat yang tidak hanya unggul dalam jumlah dan kapasitas tapi juga mutu dan kualitas, tidak hanya unggul dalam pencapaian akreditasi namun juga unggul dalam mutu tenaga kependidikan. Dengan demikian amanat Undang-undang nomor 36 tahun 2014 tentang tenaga kesehatan juga Undang-undang nomor 38 tahun 2014 tentang tenaga keperawatan terjawab dengan adanya jaminan lulusan yang professional.

Fenomena yang terjadi di Indonesia tingkat kelulusan Ukom perawat D3 Keperawatan sejak periode tahun 2018-2020 terjadi penurunan dan sangat rendah jika dibandingkan dengan beberapa negara yang tingkat kelulusannya diatas $80 \%$. Berdasarkan studi pendahuluan terhadap mahasiswa di beberapa program studi keperawatan di Bengkulu, masih ada alumni D3 Keperawatan yang retaker berkali-kali 
bahkan beberapa diantaranya ada yang retaker hingga lebih dari 5 kali. Selain itu beberapa mahasiswa juga berpendapat bahwa institusi tidak memberikan perhatian khusus pada ketidaklulusan mahasiswa dalam Uji kompetensi tersebut.

Untuk persiapan menghadapi exit exam ini mahasiswa perlu mempersiapkan diri dan tentunya perlu dukungan dari institusi untuk mencapai angka kelulusan 100\%. Hal ini tentunya perlu dipersiapkan dari awal semester agar mahasiswa terbiasa dalam menghadapi ujian dalam bentuk kasus sehingga mahasiswa terbiasa dengan soal-soal ukom. Masih banyak permasalahan yang muncul pada saat pelaksanaan uji kompetensi dilakukan, seperti ketidaksiapan mahasiswa dalam mengerjakan soal-soal kasus, penggunaan komputer yang belum paham karena exit exam dilakukan secara Computer Base Test (CBT). Solusi yang dapat dilakukan untuk membantu mahasiswa dalam menghadapi exit exam ini adalah dengan membiasakan mahasiswa mengerjakan soalsoal kasus yang sesuai dengan standar uji kompetensi, hal ini tentunya didukung oleh kemampuan dosen dalam membuat soal-soal berbentuk kasus di setiap semester. Kemudian melakukan Try out internal dan mengikuti try out nasional.

Persepsi mahasiswa terhadap uji kompetensi dianggap penting karena sebagai tolok ukur pemahaman mahasiswa terhadap uji kompetensi. Tidak adanya pembekalan mengenai uji kompetensi exit exam dan tidak ikut sertanya try out uji kompetensi akan menimbulkan persepsi yang berbeda-beda pada calon peserta uji kompetensi dalam menghadapi exit exam.

\section{METODE}

Jenis penelitian ini adalah penelitian survei analitik dengan model pendekatan cross sectional study dengan tujuan untuk mengatahui Faktor-faktor yang mempengaruhi kelulusan dalam menghadapi uji kompetensi exit exam pada mahasiswa 3 keperawatan. Populasi pada penelitian ini adalah mahasiswa semester 6 yang mengikuti exit exam. Cara pengambilan sampel yang digunakan adalah simple random sampling, jumlah sampel pada penelitian ini sebanyak 110 orang yang berasal dari Poltekkes Kemenkes Bengkulu, D3 Keperawatan UNIB, Poltekkes Kemenkes Tanjung Karang, Poltekkes Kemenkes Riau. Jenis data dalam penelitian yang penulis gunakan adalah data primer dan data sekunder. Instrumen yang digunakan dalam penelitian ini yaitu dengan kuesioner menggunakan google form. 


\section{HASIL}

Penelitian dilaksanakan dari bulan Juli sampai November 2021 . Populasi pada penelitian ini mahasiswa semester 6 prodi D3 Keperawatan di Provinsi Bengkulu, lampung dan Riau. Jumlah sampel sebanyak 110 mahasiswa D3 Keperawatan. Data dikumpulkan melalui kuesioner yang dibagikan melalui goolge form.

Hasil penelitian menunjukkan karakteristik responden yang meliputi jenis kelamin, asal institusi, kesiapan institusi. Digambarkan pada tabel berikut ini :

Tabel 1

Distribusi Karakteristik Responden Berdasarkan Jenis Kelamin dan Asal Institusi

\begin{tabular}{lcc}
\hline \multicolumn{1}{c}{ Variabel } & Frekuensi (N) & Presentasi (\%) \\
\hline Jenis Kelamin & & \\
Laki-laki & 16 & $14,5 \%$ \\
Perempuan & 94 & $85,5 \%$ \\
\hline Asal Institusi & & \\
\hline D3 Keperawatan UNIB & 45 & $40,9 \%$ \\
\hline PoltekkesBengkulu & 33 & $30,0 \%$ \\
\hline Poltekkes Riau & 22 & $20,0 \%$ \\
\hline Poltekkes Tanjung Karang & 10 & $9,1 \%$ \\
\hline
\end{tabular}

Tabel 2 menunjukkan sebagian besar $(85,5 \%)$ responden berjenis kelamin perempuan. Hampir sebagian $(40,9 \%)$ responden berasal dari UNIB dan sebagian kecil $(9,1 \%)$ berasal dari Poltekkes Tanjung Karang

Tabel 2

Distribusi Kesiapan Institusi Dalam Menghadapi Exit

\begin{tabular}{lcc}
\hline \multicolumn{1}{c}{ Variabel } & Frekuensi (N) & Persentase (\%) \\
\hline Institusi & & \\
Siap & 59 & $53,6 \%$ \\
Tidak Siap & 51 & $46,4 \%$ \\
\hline
\end{tabular}

Tabel 3

Distribusi Kelulusan UKOM Exit Exam Tahun 2021

INSTITUSI

UKOM EXIT EXAM KOMPETEN TIDAKKOMPETEN

\begin{tabular}{lccc}
\hline D3 Keperawatan & $43(95,5 \%)$ & 2 & 45 \\
$\begin{array}{l}\text { UNIB } \\
\text { Poltekkes } \\
\text { Bengkulu Kemenkes }\end{array}$ & $31(93,9 \%)$ & 2 & 33 \\
$\begin{array}{l}\text { Poltekkes } \\
\text { Riau Kemenkes }\end{array}$ & $20(90,9 \%)$ & 2 & 22 \\
$\begin{array}{l}\text { Poltekkes Kemenkes } \\
\text { Tanjung Karang }\end{array}$ & $10(100 \%)$ & 0 & 10
\end{tabular}


Tabel 3 menunjukkan bahwa (95,5\%) kelulusan D3 Keperawatan UNIB, (93,9\%) kelulusan Poltekkes Bengkulu, (90,9\%) kelulusanan Poltekkes Kemenkes Riau, dan $(100 \%)$ kelulusan Poltekkes Tanjung Karang.

Tabel 4

Hubugan Kesiapan Institusi dengan Kelulusan Exit Exam UKOM Tahun 2021

\begin{tabular}{lrcrl}
\hline KESIAPAN & \multicolumn{2}{c}{ UKOM EXIT EXAM } & TOTAL & $\begin{array}{l}\text { Fisher's } \\
\text { Exact Tes }\end{array}$ \\
& KOMPETEN & TIDAK KOMPETEN & & \\
\hline Institusi & & & 59 & 0,589 \\
Siap & $56(94,9 \%)$ & $3(5,1 \%)$ & 51 & \\
Tidak Siap & $48(94,1 \%)$ & $3(5,9 \%)$ & & \\
\hline
\end{tabular}

Tabel 4 Hasil analisis menunjukkan bahwa dari 59 orang responden yang menyatakan institusi siap, terdapat $56(94,9 \%)$ responden yang kompeten. Sedangkan dari 51 menyatakan institusi tidak siap, terdapat $48(94,1 \%)$ responden yang kompeten. Dari uji Chi-Square didapatkan nilai fisher's exact tes $=0,589$ lebih besar dari $\alpha 0,05$, berarti tidak ada hubungan kesiapan institusi dalam kelulusan exit exam.

\section{PEMBAHASAN}

Hasil penelitian menujukkan bahwa gambaran karakteristik responden berdasarkan jenis kelamin sebagian besar berjenis kelamin perempuan. Sebanyak 40,9\% responden berasal dari D3 Keperawatan UNIB, 30\% responden dari Poltekkes Kemenkes Bengkulu, 20\% responden dari Poltekkes Riau dan 9,1\% responden dari Poltekkes Kemenkes Tanjung karang.

Hasil penelitian menunjukkan tidak hubungan kesiapan institusi dengan kelulusan UKOM exit Exam dengan nila fisher exact 0,589. Hasil penelitian ini sejalan dengan penelitian Deby Zulkarnain \& Rahardian Syah (2018) yang menunjukkan tidak ada hubungan faktor eksternal dengan kelulusan ukom pada mahasiswa Keperawatan STIKES Jendral Achmad Yani Yogyakarta.

Hasil penelitian Sears, Othman, \& Mahoney, (2015) menunjukkan bahwa keberhasilan seseorang lulus exit exam dapat dipengaruhi oleh banyak faktor seperti faktor akademik, faktor kognitif, dan faktor individu. Beberapa faktor yang berpengaruh terhadap keberhasilan uji kompetensi dari segi persiapan mahasiswa dalam belajar ialah motivasi, kemampuan membaca, catatan, manajemen waktu, dan kemampuan berpikir kritis (Professional Development and Conferencing Services, Faculty of Medicine, Memorial University of Newfoundland, 2010). Strategi lain yang bisa digunakan dalam meningkatkan kelulusan mahasiswa dalam menghadapai exit exam adalah dengan 
menfokuskan pada bimbingan mahasiswa, mengatasi kecemasan dan mengembangkan strategi pada program remedial (Hyland, 2012).

Ada beberapa strategi yang bisa dilakukan untuk meningkatan kelulusan mahasiswa dalam ukom exit exam seperti ketersediaan sarana dan prasarana dalam menghadapi ujian seperti tersedianya laboratorium CBT dan strategi yang dilakukan dosen dalam mempersiapkan mahasiswa dalam menghadapi UKOM exit, kesiapan intitusi untuk memotivasi mahasiswa dalam menghadapi ujian kompetensi exit exam dapat membantu mahasiswa dalam menyiapkan mental saat menghadapi ujian. Dan adanya upaya institusi mengadakan bimbingan belajar atau pembekalan dalam menghadapi uji kompetensi sehingga mahasiswa memiliki persiapan yang matang dalam menghadapi ujian. Institusi mewajibkan mahasiswa untuk mengikuti try out yang diadakan oleh Asosiasi atau kemendikbud, dan institusi mengadakan try out internal setiap semester. Membuat diskusi kelompok dalam membahas soal-soal berstandar ukom sehimgga mahasiswa sering terpapar dengan soal-soal yang akan meningkatkan pemahaman mahasiswa dalam menghadapi ujian exit exam. Menurut Johnson, (2015); Kang et al.,( 2016) strategi yang dilakukan institusi di luar negeri agar tingkat kelulusan mencapai standar yang ditentukan diantaranya adalah dengan mendesain kurikulum khusus.

Hasil kelulusan ukom exit exam saat ini penilaiannya ditentukan dengan persentase $60 \%$ nilai IPK dan $40 \%$ nilai hasil UKOM. Hal ini menunjukkan betapa pentingnya mahasiswa mempersiapkan diri secara matang dalam meningkatkan kemampuan kognitif, afektif dan psikomotor sehingga mahasiswa dapat memperoleh nilai yang baik setiap semesternya. Hasil penelitian yang dilakukan Alvin Abdillah (2016) menunjukkan bahwa ada hubungan antara try out, IPK, gaya belajar dengan kelulusan UKOM pada mahasiswa Ners. Penelitian Ayu Hartina, dkk (2018) juga menunjukkan hasil bahwa faktor-faktor yang mempengaruhi kelulusan ukom pada mahasiswa Ners di regional Sulawesi adalah kesiapan, tryout, dan Prestasi Akademik.

Hasil penelitian juga menunjukkan bahwa sebagian besar mahasiswa mengatakan bahwa kelengkapan sarana dn sarana dalam proses pembelajaran, ketersedian laboratorium CBT dan bimbingan belajar menghadapi ukom sangat membantu mereka dalam pemahaman dan kesiapan dalam menghadapi UKOM exit exam 


\section{SIMPULAN DAN SARAN}

Hasil penelitian menunjukan sebagian besar responden berjenis kelamin perempuan, tidak ada hubungan kesiapan institusi dengan kelulusan ukom.

Berdasarkan hasil penelitian untuk tercapainya tingkat keberhasilan dalam menghadapi UKOM exit Exam maka harus ada sinergi antara kesiapan institusi, dosen dan mahasiswa dalam menghadapi UKOM memperbanyak latihan dan membahas soalsoal berstandar UKOM, melakukan try out internal dan bimbingan belajar, serta aktif dalam mengikuti try out yang diselenggarakan oleh asosiasi maupun try out nasional 


\section{DAFTAR RUJUKAN}

Abdillah, A. (2016). Analisis faktor-faktor yang mempengaruhi kelulusan uji kompetensi ners Indonesia. Jurnal Penelitian Administrasi Publik, 2(2): 373-380.

Benefiel, D. (2011). The story of nurse licensure. Nurse Educator, Lippincott Williams \& Wilkins, 36(1), 16-20. https://doi.org/10.1097/ NNE.0b013e3182001e 82

Brodersen, L. D., \& Mills, A. C. (2014). A Comparison of Two Nursing Program Exit Exams That Predict Outcome. CIN: Computers, Informatics, Nursing \&, 32(8), 404-412. https://doi. org/10.1097/CIN.0000000000000081

Hartina, A., Tahir, T., Nurdin, N., \& Djafar, M. (2018). Faktor Yang Berhubungan Dengan Kelulusan Uji Kompetensi Ners Indonesia (Ukni) Di Regional Sulawesi. Jurnal Persatuan Perawat Nasional Indonesia (JPPNI), 2(2), 65. https://doi. org/10.32419/jppni.v2i2.84

Hooper, J. I., \& Ayars, V. D. (2017). How Texas Nurs- Jurnal Keperawatan Muhammadiyah Edisi Khusus 201968 ing Education Programs Increased NCLEX Pass Rates and Improved Programming. Journal of Nursing Regulation, 8(3), 53-58. https://doi. org/10.1016/S2155-8256(17)30160-6

Kariasa, I. M., Tahir, T., Rahayu, U., Santoso, A., Slametiningsih, Soesanto, E.,Wahyuni, S. (2018). Sinersi Hadirkan Sukses Uji Kompetensi Ners Indonesia. Jakarta: Asosiasi Institusi Pendidikan Ners Indonesia (AIPNI).

Kholifah, S., \& Kusumawati, W. (2016). Hambatan Lulusan Ners Dalam Menghadapi Uji Kompetensi Ners Indonesia. The Indonesian Journal of Health Science,7(1),40-47.

Notoatmojo, (2014). Metodologi Penelitian Kesehatan. Jakarta:Rineka Cipta.

Panitia Ujian Kompetensi Nasional,( 2018). Buku Pedoman Uji Kompetensi Diploma 3 Keperawatan.

Peraturan Menteri Pendidikan dan Kebudayaan RI No. 2 Tahun 2020 tentang Tata Cara Pelaksanaan Uji Kompetensi Mahasiswa Bidang Kesehatan

Shoemaker, J. R., Chavez, R. A., Keane, P., \& Butz, S. (2017). Effective Utilization of Computerized Curricular Assistive, 43081 (April), 194-200.

Sugiarto. 2001. Teknik Sampling. Jakarta: PT. Gramedia Pustaka Utama.

Sugiyono. 2011. Metode Penelitian Administratif. Bandung: Alfabeta

Suyono, \& Hariyanto.(2015). Implementasi Belajar \& Pembelajaran. Bandung: Remaja Rosdakarya. 
Undang-Undang Republik Indonesia Nomor 38 Tahun 2014 Tentang Keperawatan (2014). Jakarta. Retrieved from www.kemenkopmk.go.id/content/uu-nomor-38-tahun-2014 